\section{How Much is Enough?}

THE most respectable of all numbers games is the prediction of population, as in the United Kingdom. Unlike other forms of gaming, bingo or blackjack, for example, trying to tell how many young people will need desks in schools ten years ahead, or how many older people will need hospital beds in which to be sick, tends to be invested with all the propriety of social purpose. A demographer is a social scientist, not a gambler-that, at least, is what his friends and employers say. The latest attempt to estimate the future population of the United Kingdom, Population Projections 1970-2010 prepared by the Government Actuary (HMSO, £1.20), goes a long way to suggest that the truth may be on the other side of the coin, and that the time has come for those who would predict the future population of a nation to throw a handful of dead leaves in the air and then count the number falling right side up.

The Government Actuary (a statistical analogue of an astronomer-royal not to be confused with the head of the British Government's Statistical Service) has on this occasion set out to estimate the population of the United Kingdom and the several parts of it (Ulster included) in the next forty years. Up to a point, the exercise makes sense, for more than half of the people who will still be alive in Britain in AD 2000 are alive already. Many of them are even middle-aged. To that extent, it is easy enough to estimate the population of old people's homes at the turn of the century. Unhappily, it is much more difficult to estimate how many young people there will be. Especially now that it has become unfashionable for the parents of large families to declare in public how great a claim they have made on future resources, and with women's liberation just around the corner, not even a Government Actuary can be sure what he intends by a population prediction for the year 2000 .

The latest prediction is not merely uncertain but also as unoriginal as anybody could wish. For the United Kingdom as a whole, the population is expected to increase steadily from 55.8 million in 1970 (halfway through the year) to 58.9 million in $1981,62.3$ million in 1991 and 66.5 million in 2001. In other words, the increase of population is estimated to be about 20 per cent in the course of the next thirty years. In the circumstances, it is only proper to ask how accurate these estimates may be.

In the thirty years between now and the end of the century, rather more than 20 million people will die. Emigration will account for about 2 million more even if the growing political integration in Western Europe does not further stimulate the tendency for people born in Britain to earn their living abroad. During the same period and on the assumptions which the Government Actuary has made about the future fertility of the United Kingdom, something like 25 million people will be born or will immigrate into the United Kingdom. Quite apart from the uncertainties which there must be about the future trend of fertility, the balance of emigration and immigration may be a source of great error-the 1971 census shows an error of 500,000 on this score in the past decade. In ordinary life, in a physics laboratory for example, nobody would complain if the Government Actuary had thrown up his hands in the face of these uncertainties and had declared that forecasting of the population of the United Kingdom thirty years from now would be impossible. The demographers, unfortunately, expect no less of themselves and their colleagues. The trouble, of course, is that the errors in such a process are so great that the forecast is in part at least a kind of guess.

Quite understandably, 'the Government Actuary bemoans the way in which the fertility of the women of the United Kingdom has fluctuated in the past few years. In the space of a quarter of a century, the number of births each year has fluctuated between less than 800,000 and rather more than 1 million.

In the mid-1960s, the official demographers were so impressed by the rapid growth of fertility that they were seduced into estimates of the population of the United Kingdom amounting to close on 80 million by $2000-$ estimates so alarming that they have since become a part of the popular mythology of population growth. In the event, not merely fertility but the number of births each year in the United Kingdom has since fallen steadily, yet even now the latest estimate of population is based on the assumption that this tendency will be reversed forthwith. In these circumstances, very few of those who put money on racehorses would be persuaded that it can be sensible to back the most. bullish of the estimates which the Government Actuary has put forward. It is at least as good a bet that the population of the United Kingdom will be the same at the end of the century as it is at present. If there is a change, it will most probably consist of an increase of the proportions of old people and a corresponding decrease of young people.

The moral, which should be heeded not merely by the Government Actuary but by the three registrar-generals of the United Kingdom, not to mention such organizations as the Census Bureau in the United States and the Population Commission of the United Nations, is that there are serious limits on attempts to forecast the population of countries, regions or the world as a whole. It may be possible in advanced societies, where the death rate is reasonably predictable, to estimate the numbers of schoolchildren three or four years ahead or the numbers of old-age pensioners fifty years ahead, but the estimation of how many young people there will be by the end of the century requires a much better understanding of the motives which persuade couples in advanced societies to have children or to forswear them as well as a certain amount of luck. As it happens, this is the most notoriously unreliable parameter in the demography of the future. In the circumstances, might it not be a great saving of public funds if the Government Actuary and the other organizations which are tempted to follow in these inelegant footsteps - on this occasion, the Actuary has not even put forward an estimate of the extent to which he thinks his estimate may be uncertain - were to settle for more modest but more realistic goals in forecasting the population? 